\title{
Active decompression improves the haemodynamic state during cardiopulmonary resuscitation
}

\author{
U M Guly, C E Robertson
}

\begin{abstract}
Objective-To examine whether use of the active compression-decompression device improves the haemodynamics of cardiopulmonary resuscitation compared with those of conventional cardiopulmonary resuscitation.
\end{abstract}

Design-Prospective crossover study. Setting-The accident and emergency department of a university teaching hospital.

Patients-36 adult patients with nontraumatic, normothermic, out of hospital cardiac arrest.

Interventions-Cardiopulmonary resuscitation was performed during resuscitation in alternating $3 \mathrm{~min}$ cycles of conventional and active compressiondecompression cardiopulmonary resuscitation.

Main outcome measures-The end tidal carbon dioxide $\left(\mathrm{ETCO}_{2}\right)$, femoral arterial pressure, and acid-base analysis of central venous blood measured during the last $30 \mathrm{~s}$ of each 3 minute cardiopulmonary resuscitation cycle.

Results-ETCO $\mathrm{C}_{2}$ was monitored in 36 patients during conventional and active compression-decompression cardiopulmonary resuscitation. Active compression-decompression cardiopulmonary resuscitation caused a significant increase in $\mathrm{ETCO}_{2}(\mathrm{P}<0.0002)$, indicating improved cardiac output. Arterial pressure measurement was carried out in 10 patients. Systolic pressure was significantly greater with active compressiondecompression than conventional cardiopulmonary resuscitation $(\mathbf{P}<$ 0.007). Central venous blood was taken for acid-base analysis in 11 patients. There was a significant increase in the central venous hydrogen ion concentration $(P=0.025)$ with rises in the partial pressures of carbon dioxide and oxygen, suggesting improved venous return.

Conclusions-This study confirms that active compression-decompression cardiopulmonary resuscitation is associated with better haemodynamic status than conventional resuscitation.

(Br Heart f 1995;73:372-376)
Keywords: cardiopulmonary resuscitation; active compression-decompression device; haemodynamic state during cardiopulmonary resuscitation

Closed chest cardiopulmonary resuscitation has been the standard method of maintaining blood flow after cardiac arrest since it was described by Kouwenhoven et $a l^{1}$ in 1960 but it is well recognised that it does not restore a normal circulation. Studies in animal models and in man have shown the total cardiac output during CPR to be less than $20 \%$ of nor$\mathrm{mal}^{23}$ and cerebral circulation to be only $10-20 \%$ of the level obtained with a spontaneous circulation. ${ }^{45}$ As a consequence neurologically intact survival after prolonged cardiopulmonary resuscitation is uncommon. ${ }^{6}$

In 1992 Cohen $e t a l^{7}$ at the University of California described a new method of cardiopulmonary resuscitation, namely active compression-decompression cardiopulmonary resuscitation using a device that combines a broad handle with a suction cup. Active compression-decompression cardiopulmonary resuscitation has a compression phase, as in conventional cardiopulmonary resuscitation, but the passive relaxation phase is replaced by active decompression in which the chest wall is lifted upwards by the suction cup. Initial studies in a canine model ${ }^{8}$ and man $^{7}$ have suggested improved cardiac output with active compression-decompression cardiopulmonary resuscitation. A randomised trial comparing active compression-decompression resuscitation and conventional cardiopulmonary resuscitation in patients with out of hospital cardiac arrest demonstrated improved shortterm survival but no significant increase in survival to hospital discharge. ${ }^{9}$

We compared conventional and active compression-decompression cardiopulmonary resuscitation in adult patients treated for out of hospital cardiac arrest in an accident and emergency ( $A \& E$ ) department. We assessed the efficacy of cardiopulmonary resuscitation using end tidal carbon dioxide $\left(\mathrm{ETCO}_{2}\right)$, which reflects cardiac output during cardiopulmonary resuscitation, arterial pressure, and acid-base analysis.

Patients and methods PATIENTS

We studied 36 adult patients with nontraumatic, normothermic, out of hospital 
Figure 1 Changes in mean end tidal carbon dioxide $\left(\mathrm{ETCO}_{2}\right)$ with conventional and active compression-decompression $(A C D)$ cardiopulmonary resuscitation (CPR).

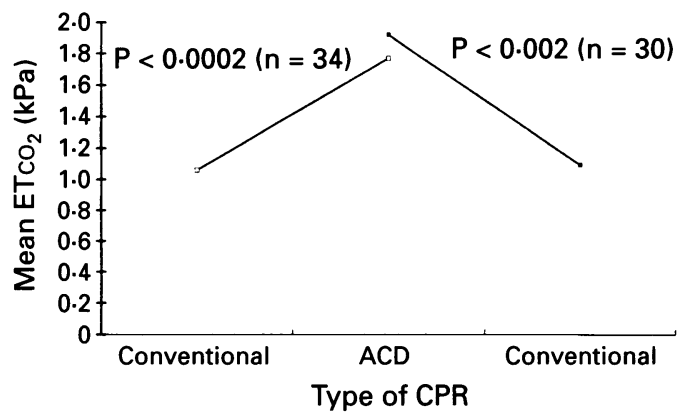

cardiac arrest treated in the $A \& E$ department of the Royal Infirmary of Edinburgh. Some $83 \%$ of patients were male and their age range was 29-83 (mean 65) years. The study was approved by Lothian Health Board Committee.

The cardiac arrest was witnessed in 30 $(83 \%)$ of the patients and $16(44 \%)$ had received cardiopulmonary resuscitation from bystanders. All patients were treated by Scottish Ambulance Service technicians or paramedics equipped with a semiautomatic defibrillator before transfer to the $A \& E$ department. The mean (range) interval between collapse and ambulance arrival was 9 (0-20) $\mathrm{min}$ and between collapse and the start of the study $37 \cdot 5(16-60) \mathrm{min}$.

\section{METHODS}

Tracheal intubation was performed after the patient's arrival in the A\&E department if this had not been achieved before hospitalisation. Cardiopulmonary resuscitation was performed in alternating 3 min cycles of conventional cardiopulmonary resuscitation using a mechanical thumper (Thumper, model 1004; Michigan Instruments) and active compression-decompression cardiopulmonary resuscitation (CardioPump, Ambù International) until either there was a return of spontaneous circulation or resuscitation was discontinued. Chest compression was performed at a rate of $80 /$ min for each technique with a chest compression to ventilation ratio of $5: 1$. Ventilation was maintained throughout with a fractional inspired oxygen concentration of 1.0 using the Thumper ventilator set to an inflation pressure of $30 \mathrm{~cm}$ water.

ETCO $_{2}$ was monitored using an Ohmeda 5250 RGM capnometer. A right femoral arterial cannula was sited, arterial pressure recorded (Propaq 106 monitor; Protocol
Systems, Oregon, USA), and a pressure wave trace obtained. A central venous catheter was placed through either the right subclavian or right internal jugular vein and blood was taken from the catheter for acid-base analysis.

$\mathrm{ETCO}_{2}$, and femoral arterial systolic and diastolic pressures were recorded and central venous blood was taken for acid-base analysis at the end of each $3 \mathrm{~min}$ cardiopulmonary resuscitation cycle. Patients were excluded from the analysis if they regained a spontaneous circulation or if resuscitation was discontinued before completing a full $3 \mathrm{~min}$ of conventional and active compression-decompression cardiopulmonary resuscitation. Patients were given sodium bicarbonate were excluded from the analysis.

Resuscitation was performed according to the European Resuscitation Council guidelines ${ }^{10}$ and the resuscitation team leader remained independent of the study.

The results were analysed using a paired two tailed $t$ test.

\section{Results}

$\mathrm{ETCO}_{2}$

$\mathrm{ETCO}_{2}$ was used as a non-invasive marker of cardiac output in 36 patients. The mean $\mathrm{ETCO}_{2}$ increased significantly on changing from conventional to active compressiondecompression cardiopulmonary resuscitation (fig 1).

Resuscitation was continued in 30 patients to allow recording of the $\mathrm{ETCO}_{2}$ at the end of a further $3 \mathrm{~min}$ of conventional cardiopulmonary resuscitation. The $\mathrm{ETCO}_{2}$ decreased significantly in these patients on returning to conventional cardiopulmonary resuscitation (fig 1).

This pattern repeated itself in patients in whom resuscitation continued for further cycles of cardiopulmonary resuscitation, $\mathrm{ETCO}_{2}$ increasing with each change from conventional to active compression-decompression cardiopulmonary resuscitation and decreasing on the return to conventional cardiopulmonary resuscitation (fig 2). Some 32 $(89 \%)$ of the 36 patients had improved $\mathrm{ETCO}_{2}$ with active compression-decompression cardiopulmonary resuscitation.

\section{ARTERIAL PRESSURE}

Arterial pressure was measured through a femoral arterial line in 10 patients. The systolic and diastolic pressures at the end of the
Figure 2 Changes in end tidal carbon dioxide $\left(E T \mathrm{CO}_{2}\right)$ in one patient who had repeated cycles of conventional and active compression-decompression cardiopulmonary resuscitation.

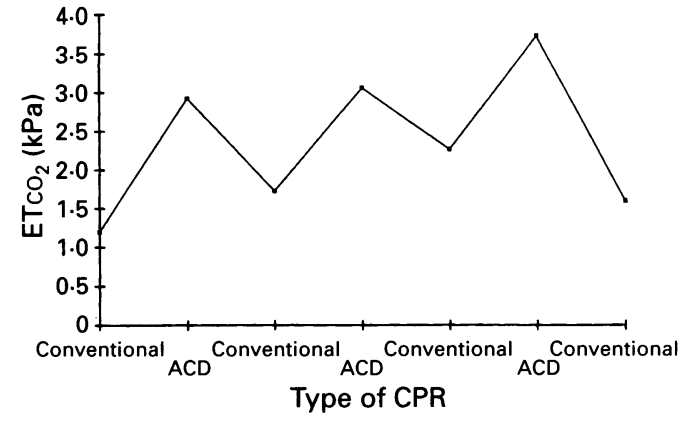

Table 1 Arterial pressure during cardiopulmonary resuscitation

\begin{tabular}{lll}
\hline & $\begin{array}{l}\text { Arterial pressure } \\
\text { Systolic }\end{array}$ & Diastolic \\
\hline $\begin{array}{c}\text { Conventional cardio- } \\
\text { pulmonary resuscitation }\end{array}$ & 52 & 31 \\
$\begin{array}{c}\text { Active compression- } \\
\text { decompression cardio- } \\
\text { pulmonary resuscitation }\end{array}$ & 95 & 34 \\
$\mathrm{P}$ & $<0.007$ & $\mathrm{NS}$ \\
\hline $\mathrm{NS}$, not significant. & &
\end{tabular}


Figure 3 Arterial pressure traces. (A) Conventional cardiopulmonary resuscitation. (B) active compressiondecompression cardiopulmonary resuscitation.

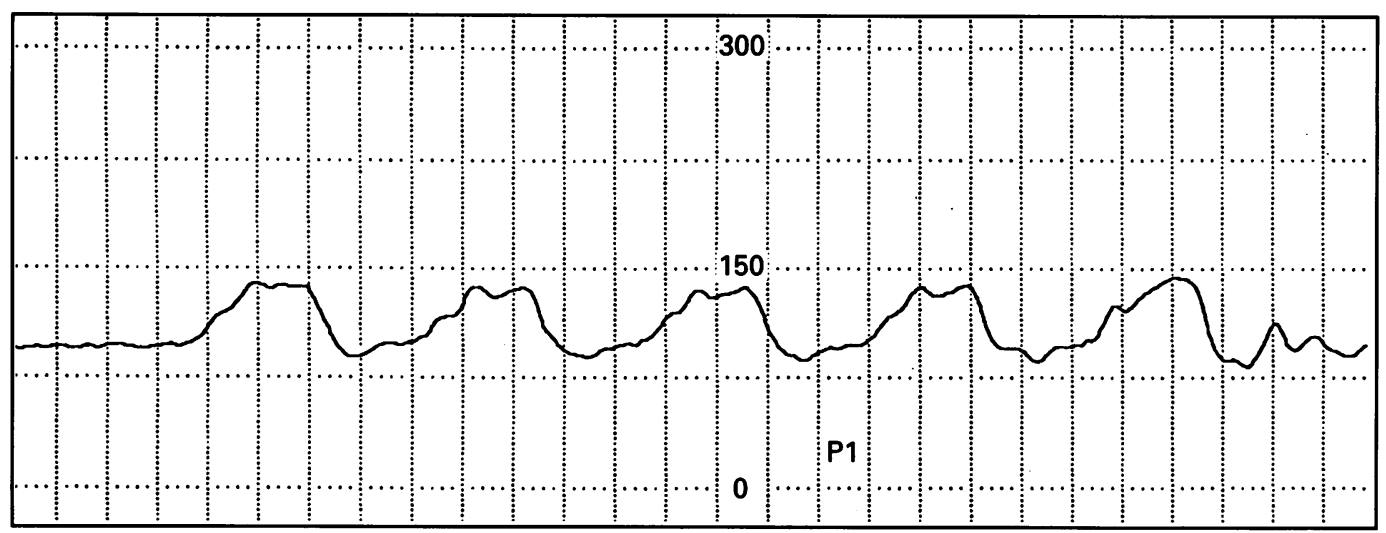

A

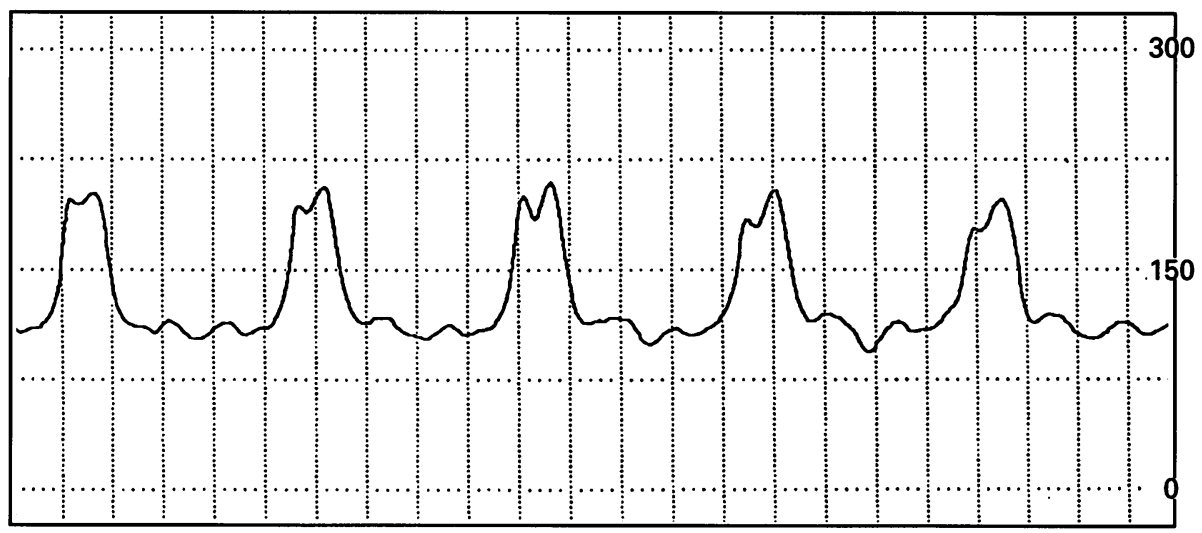

B

third minute of the first cycles of conventional and active compression-decompression cardiopulmonary resuscitation were recorded. The systolic pressure was greater with active compression-decompression than conventional cardiopulmonary resuscitation in nine of the 10 patients. The mean systolic pressure was significantly increased with the new technique. There was no significant difference in the diastolic pressures achieved with the two methods of cardiopulmonary resuscitation (table 1).

The shape of the arterial pressure wave differed markedly with the two techniques (fig 3). The compression phase during active compression-decompression cardiopulmonary resuscitation resulted in a steep increase in arterial pressure with a marked notch while conventional cardiopulmonary resuscitation was associated with a much slower rise in pressure.

CENTRAL VENOUS ACID-BASE STATUS

The acid-base status of central venous blood

Table 2 Central venous acid-base status

\begin{tabular}{llll}
\hline & $\begin{array}{l}\text { Conventional } \\
\text { cardio- } \\
\text { pulmonary } \\
\text { resuscitation }\end{array}$ & $\begin{array}{l}\text { Active compression- } \\
\text { decompression } \\
\text { cardiopulmonary } \\
\text { resuscitation }\end{array}$ & \\
\hline Hydrogen ion concentration $(\mathrm{mmol} / \mathrm{l})$ & $\mathbf{8 8 . 6}$ & $102 \cdot 4$ & P value \\
Partial pressure of carbon dioxide $(\mathrm{kPa})$ & $8 \cdot 6$ & 9.9 & $0 \cdot 025$ \\
Partial pressure of oxygen $(\mathrm{kPa})$ & $4 \cdot 7$ & $6 \cdot 3$ & $\mathrm{NS}(0 \cdot 13)$ \\
Bicarbonate concentration $(\mathrm{mmol} / \mathrm{l})$ & 18.5 & $17 \cdot 1$ & $\mathrm{NS}(0 \cdot 14)$ \\
\hline
\end{tabular}

NS, not significant. was assessed in 11 patients. Blood was taken from a central venous catheter at the end of the first two cardiopulmonary resuscitation cycles for acid-base analysis. There was a significant increase in the hydrogen ion concentration on changing from conventional to active compression-decompression cardiopulmonary resuscitation, and a rise in the partial pressures of oxygen $\left(\mathrm{PO}_{2}\right)$ and carbon dioxide $\left(\mathrm{PCO}_{2}\right)$, although these did not attain statistical significance (table 2).

\section{Discussion}

Our results confirm that active compressiondecompression cardiopulmonary resuscitation is associated with better haemodynamic status than conventional cardiopulmonary resuscitation, as demonstrated by improved $\mathrm{ETCO}_{2}$ and systolic pressure and an increase in the products of metabolism and $\mathrm{PO}_{2}$ in central venous blood. We used a mechanical thumper to administer conventional cardiopulmonary resuscitation. This has the advantage of being able to be programmed to give consistent chest compression at the rate and depth recommended in the guidelines of the European Resuscitation Council. ${ }^{11}$ Studies comparing cardiopulmonary resuscitation using a thumper and manual cardiopulmonary resuscitation confirm similar patterns of blood flow ${ }^{12}$ and haemodynamic state $^{13}$ with the two techniques. The amount of carbon dioxide $\left(\mathrm{CO}_{2}\right)$ in expired air depends on $\mathrm{CO}_{2}$ production, ventilation, and 
pulmonary blood flow. $\mathrm{ETCO}_{2}$ is a reliable non-invasive indicator of cardiac output during low cardiac output states such as during cardiopulmonary resuscitation as pulmonary blood flow is the limiting factor for $\mathrm{CO}_{2}$ excretion. Production of $\mathrm{CO}_{2}$ in patients with cardiac arrest is constant if sodium bicarbonate is not administered, and therefore under conditions of constant ventilation $\mathrm{ETCO}_{2}$ depends on cardiac output, not arterial $\mathrm{CO}_{2}$ tension. ${ }^{14-18}$ Increased $\mathrm{ETCO}_{2}$ during cardiopulmonary resuscitation is associated with increased cerebral blood flow, ${ }^{17}$ coronary perfusion pressure, ${ }^{18}$ and the likelihood of successful resuscitation. ${ }^{19}$ In this study changing from conventional to active compressiondecompression cardiopulmonary resuscitation was associated with a significant increase in $\mathrm{ETCO}_{2}$. There was a significant decrease in $\mathrm{ETCO}_{2}$ on returning to conventional resuscitation. This indicates improved cardiac output with active compression-decompression cardiopulmonary resuscitation. $\mathrm{ETCO}_{2}$ during cardiopulmonary resuscitation is dependent on cardiac output only if ventilation remains unchanged. Throughout the study the minute ventilation was maintained at a constant level using the Thumper ventilator. Some ventilation is achieved using the active compressiondecompression device, ${ }^{7}$ but this would have increased the minute ventilation and hence tended to reduce the $\mathrm{ETCO}_{2}$ during active compression-decompression cardiopulmonary resuscitation compared with that of conventional resuscitation. This may have introduced a reduction in the apparent improvement observed with active compression-decompression cardiopulmonary resuscitation but does not invalidate our conclusions.

There was an improvement in systolic pressure, closer to normal physiological levels on changing to active compression-decompression cardiopulmonary resuscitation in nine of 10 patients studied with arterial pressure monitoring. This was statistically significant and confirms results obtained by Cohen et $a l^{78}$ in a canine model and in man. The presence of a pressure wave during cardiopulmonary resuscitation does not necessarily indicate anterograde blood flow. We have previously demonstrated increased velocity of forward blood flow with active compressiondecompression cardiopulmonary resuscitation using transoesophageal echocardiography. ${ }^{12}$ This combined with the $\mathrm{ETCO}_{2}$ evidence of increased cardiac output indicates improved blood flow and hence perfusion. There was no significant difference in the diastolic pressures achieved with the two methods. The mean duration of resuscitation in the study patients after arrival in the $A \& E$ department was under $20 \mathrm{~min}$ and did not allow for direct measurement of coronary perfusion pressure, although the increase in $\mathrm{ETCO}_{2}$ suggests an improvement with active compressiondecompression cardiopulmonary resuscitation. ${ }^{18}$

There was a significant increase in the hydrogen ion concentration in central venous blood on changing from conventional to active compression-decompression cardiopulmonary resuscitation, and smaller rises in the $\mathrm{PCO}_{2}$ and $\mathrm{PO}_{2}$ that did not attain statistical significance. The increase in the concentration of the products of metabolism is likely to reflect improved venous return to the thorax. Our group ${ }^{12}$ and others ${ }^{7}$ have previously demonstrated an increase in right atrial filling on changing to active compression-decompression cardiopulmonary resuscitation using transoesophageal echocardiography. We suggest that increased venous return associated with the active decompression phase enables active compression-decompression cardiopulmonary resuscitation to produce an improvement in cardiac output.

With an increase in cardiac output it would be expected that the central venous $\mathrm{PO}_{2}$ would increase. The increase that we demonstrated did not attain statistical significance but this could be the result of the small number of patients in whom acid-base analysis of central venous blood was performed.

During the study we experienced some problems performing active compressiondecompression cardiopulmonary resuscitation in the setting of an $A \& E$ department. The technique is physically tiring and most of our department staff were exhausted after performing $3 \mathrm{~min}$ of active compression-decompression cardiopulmonary resuscitation and would have been unable to continue if required to do so. A significant number of staff were unable to complete even $1 \mathrm{~min}$ of active compression-decompression cardiopulmonary resuscitation because of fatigue and had to be replaced. This problem has not been reported in a large prehospital study from the United States, ${ }^{9}$ but it may be relevant that the cardiopulmonary resuscitation in this study was administered by fire service emergency medical technicians who, unlike medical and nursing staff, are selected on the basis of, and required to maintain, a high degree of physical fitness. This inability of most staff to perform active compressiondecompression cardiopulmonary resuscitation for more than a few minutes has obvious implications if the technique is to be widely adopted.

While active compression-decompression cardiopulmonary resuscitation improves the haemodynamic state during cardiopulmonary resuscitation the exertion required for the technique may limit its acceptance and value. A mechanical active compression-decompression device, similar to a mechanical thumper, but incorporating an active decompression phase would be of benefit.

UMG was supported in this research by a grant from the Laerdal Foundation for Acute Medicine. The CardioPump was provided by Ambu International.

1 Kouwenhoven WB, Jude JR, Knickerbocker GG. Closed chest cardiac massage. $\mathcal{F A M A} 1960 ; 173: 1064-7$.

2 Maier GW, Tyson GS, Olsen CO, Kernstein KH, Davis JW, Conn EH, et al. The physiology of external cardiac massage: high impulse cardiopulmonary resuscitation.
Circulation 1984;70:86-101. 
3 Del Guercio LRM, Feins NR, Cohn JD, Coomaswamy RP, Wollman SB, State D. Comparison of blood flow during external and internal cardiac massage in man Circulation 1965;31(suppl 1):171-80.

4 Luce JM, Ross BK, O'Quin RJ, Culver BH, Sivarajan M, Amory DW, et al. Regional blood flow during cardiopulmonary resuscitation in dogs using simultaneous and non-simultaneous compression and ventilation. Circulation 1983;67:258-65.

5 Christensen SF, Stadeager C, Siemkowicz E. Estimation of cerebral blood flow during cardiopulmonary resuscitation in humans. Resuscitation 1990;19:115-23.

6 Caronna JJ, Finklestein S. Neurological syndromes after cardiac arrest. Stroke 1978;9:517-9.

7 Cohen TJ, Tucker KJ, Lurie KG, Redberg RF, Dutton JP, Dwyer KA, et al. Active compression-decompression JP, Dwyer KA, et al. Active compression-decompression a new method of cardio

8 Cohen TJ, Tucker KJ, Redberg RF, Lurie KG, Chin MC, Dutton JP, et al. Active compression-decompression resuscitation: a novel method of cardiopulmonary resuscitation. Am Heart $\mathcal{F} 1992 ; 124: 1145-50$.

9 Lurie KG, Shultz JJ, Callaham ML, Schwab TM, Gisch $\mathrm{T}$, Rector $\mathrm{T}$, et al. Evaluation of active compression decompression CPR in victims of out of hospital cardiac arrest. $¥ A M A$ 1994;271:1405-11.

10 Advanced Life Support Working Party of the European Resuscitation Council. Guidelines for advanced life support. Resuscitation 1992;24:111-21.

11 Basic Life Support Working Party of the European
Resuscitation Council. Guidelines for basic life support. Resuscitation 1992;24:103-110.

12 Pell ACH, Pringle SD, Guly UM, Steedman DJ, Robertson CE. Assessment of the active compressiondecompression device (ACD) in cardiopulmonary resuscitation using transoesophageal echocardiography. Resuscitation 1994;27:137-40.

13 Taylor GJ, Rubin R, Tucker M, Greene HL, Rudikoff MT, Weisfeldt ML. External cardiac compression a randomised comparison of mechanical and manual techniques. $¥ A M A$ 1978;240:644-6.

14 Weil MH, Bisere J, Trevino RP, Rackow EC. Cardiac output and end-tidal carbon dioxide. Crit Care Med 1985;13:907-9.

15 Ornato JP, Garnett AR, Glauser FL. Relationship between cardiac output and the end-tidal carbon dioxide tension. Ann Emerg Med 1990;19:1104-6.

16 Barton C, Callaham M. Lack of correlation between endtidal carbon dioxide concentrations and $\mathrm{PaCO}_{2}$ in cardiac arrest. Crit Care Med 1991;19:108-10.

17 Lewis LM, Stothert J, Standeven J, Chandel B, Kurtz M, Fortney J. Correlation of end-tidal $\mathrm{CO}_{2}$ to cerebral perusion during CPR. Ann Emerg Med 1992;21:1131-4.

18 Gazmuri RJ, von Planta M, Weil MH, Rackow EC Arterial $\mathrm{PCO}_{2}$ as an indicator of systemic perfusion during cardiopulmonary resuscitation. Crit Care Med 1989;17:237-40.

19 Callaham M, Barton C. Prediction of outcome of cardiopulmonary resuscitation from end-tidal carbon dioxide concentration. Crit Care Med 1990;18:358-62. 